\title{
Las yeguas marismeñas de Doñana: naturaleza, tradición e identidades sociales en un espacio protegido ${ }^{1}$
}

\author{
MiCHAEL D. MURPHY \\ Dpto. de Antropología. Universidad de Alabama \\ J. CARlos González Faraco \\ Dpto. de Educación. Universidad de Huelva y \\ Dpto. de Antropología. Universidad de Alabama
}

\section{RESUMEN}

Entre el extraordinario legado de tradiciones sociales y culturales del Parque Nacional de Doñana (Suroeste de Andalucía) sobresale la cría de caballos marismeños asilvestrados, no sólo por su importancia como práctica ganadera ancestral, viva e insólita, sorprendentemente poco conocida y apenas estudiada, sino también porque constituye un ejemplo eminente de las contribuciones de la cultura andaluza al resto del mundo. La ganadería marismeña es, sin duda, la matriz cultural de las tradiciones ganaderas de América. En este artículo se aborda su análisis dentro de un marco comparativo internacional del que se deduce que lo que verdaderamente distingue la cría de los caballos marismeños de otros casos paralelos en el mundo es haberse convertido en un elemento central de la cultura local, mediante emotivos procesos sociales de construcción y mantenimiento de la identidad comunitaria, en medio de reiterados conflictos con las autoridades oficiales del Parque.

Palabras clave: Caballos asilvestrados, Espacios protegidos, Parque Nacional de Doñana, Identidad social, Cultura andaluza, Invención de tradiciones.

\footnotetext{
${ }^{1}$ Queremos, en primer lugar, expresar nuestro agradecimiento a Juan J. Martínez, a Francisco Coronel y a José María Boixo, miembros de sucesivas juntas directivas de la Asociación de Criadores de Ganado Marismeño de Almonte, Huelva, y a innumerables ganaderos de esta Asociación; también, a Juan P. Castellano, del Ayuntamiento de esa misma localidad; a Rafael Cadenas y Luis Domínguez, del Parque Nacional de Doñana; a Juan Calderón, de la Estación Biológica de Doñana (CSIC); al etnólogo e historiador Ángel Cerrato, al escritor asturiano J. Antonio Silva, y especialmente al antropólogo de la Universidad de Sevilla Salvador Rodríguez Becerra; y en general a todas aquellas personas e instituciones que generosamente, de una u otra forma, nos han proporcionado información sobre este fascinante mundo de las yeguas marismeñas. Finalmente, queremos agradecer su valioso apoyo a nuestras investigaciones a la Wenner-Gren Foundation for Anthropological Research y al Departamento de Antropología de la Universidad de Alabama.
}

RDTP, LVII, 2 (2002): 5-40 


\section{SUMMARY}

The breeding of Andalusia's feral marsh horses stands out among other examples of Doñana National Park's extraordinary legacy of social and cultural traditions. This is so not only because of its importance as a venerable livestock management system, unique and vibrant still despite being surprisingly little known and scarecly studied, but also because it constitutes a notable example of the contributions that Andalusian culture has made to the rest of the world. Marsh animal husbandry is, without a doubt, the cultural matrix out of which developed the livestock traditions of the Americas. By situating this cultural complex within an international comparative framework, we argue that the human involvement with Doñana's feral horses may be distinguished from other similar cases in the world because their care and maintenance has been converted, to an extraordinary degree, into a central element of the local culture. Highly emotional social processes are involved in the construction and maintenance of a collective social identity that expresses itself in perennial conflicts with the authorities of the Park over its feral horses.

Key words: Feral Horses, Protected Landscapes, Donana National Park, Social Identity, Andalusian Culture, Invention of Tradition.

\section{INTRODUCCIÓN}

El Parque Nacional de Doñana, situado en el suroeste de Andalucía, es un espacio con grandes valores ecológicos que, sin embargo, no puede ser comprendido en toda su complejidad si sólo nos atenemos a su historia natural. Durante siglos, desde su misma conformación como territorio, sus suelos, sus cursos de agua, su fauna y su flora han venido siendo afectados por constantes intervenciones humanas de desigual origen e intensidad (Granados Corona 1989; Ojeda 1993: 10; Ojeda, Granados y otros 1993). A pesar de esta evidencia, no faltan quienes propugnan que la exclusión o la radical reducción de la actividad humana es imprescindible o, cuando menos, muy conveniente para la restauración de un supuesto equilibrio natural primitivo que, en cierto modo, habría degenerado por esa continuada presencia del hombre. Es innegable, desde luego, la necesidad de controlar la intervención humana en un ecosistema tan frágil. Pero también convendría advertir que muchos elementos ecológicos de la Doñana actual, incluso algunos de los más admirados por su calidad natural, son fruto de acciones antrópicas prolongadas (v.g. las cadenas de dunas litorales, los tupidos pinares y las propias marismas); y también que no siempre las mayores amenazas que penden sobre Doñana nacen dentro de sus mismos límites jurídicos, a veces ni siquiera en sus inmediaciones. El vertido tóxico de las minas de Aznalcóllar (Sevilla), situadas a 
decenas de kilómetros del Parque, lo ha mostrado hace pocos años dramática y elocuentemente.

El hecho es que Doñana contiene, además de un espléndido reservorio de vida necesitado de salvaguarda, un extraordinario legado de tradiciones sociales y culturales cuya importancia rebasa con creces el ámbito local. La cría de ganado en régimen extensivo, es, sin duda, una de las más prominentes (González Faraco y Murphy 2000). Las legendarias tradiciones hípicas del Nuevo Mundo (Tinker 1967; Jordan 1993), desde la Tierra del Fuego hasta el Canadá, provienen originalmente de las que, desde tiempo inmemorial, se vienen desarrollando en las Marismas del Guadalquivir.

Aunque en este artículo haremos mención a estas claras conexiones entre la ganadería marismeña y la que prosperó en América tras la llegada de los colonizadores españoles a fines del siglo Xv (González Faraco y Murphy 1999 y 2000), nos centraremos sobre todo en la discusión sobre el papel creciente e inédito, por su potencia simbólica, que está teniendo la cría de caballos asilvestrados en la cultura local de Almonte (Huelva), tal vez la comunidad más estrecha y largamente vinculada a las tradiciones ganaderas de las Marismas (Murphy 1987; González Faraco 1991a y 1991b). Para disponer de una cierta perspectiva comparada sobre el significado cultural de estas actividades en el mundo, trataremos de ofrecer primero una panorámica de las prácticas pecuarias con caballos asilvestrados en los Estados Unidos y en Gran Bretaña. Veremos cómo entre ellas hay notables paralelos y también visibles diferencias. Creemos que lo que verdaderamente distingue el caso singular de los caballos marismeños de esas otras tradiciones es haberse convertido en un elemento central de la cultura comunitaria. Mientras que los mustangs, por ejemplo, son iconos culturales para el conjunto de la nación americana, las yeguas de las Marismas de Doñana, que desde hace tiempo han dejado de representar una actividad primordialmente económica, se han visto envueltas, en los últimos años, en emotivos procesos sociales de construcción y afianzamiento de la identidad local. Nos preguntamos, y ésta es una cuestión que también atraerá nuestro interés, si con las yeguas marismeñas llegará alguna vez a suceder algo similar a lo acontecido con la multitudinaria devoción a la Virgen del $\operatorname{Rocío}^{2}$, que, siendo en su ori-

\footnotetext{
${ }^{2}$ La Romería anual que por Pentecostés se desarrolla en torno al santuario de esta Virgen suele convocar, según las cifras oficiales, en torno a un millón de peregrinos. Muchos de ellos acuden con alguna de las 99 hermandades que "hacen el camino" hasta la Aldea del Rocío, municipio de Almonte (Huelva), atravesando tierras del Parque Nacional y del Parque Natural de Doñana. Véase Murphy y González Faraco (1996b y 2002a).
} 
gen un culto local de esa misma población onubense, ha logrado propagarse por toda Andalucía e, incluso, más allá (Rodríguez Becerra 1989; Moreno 1995).

\section{ENTRE LA NATURALEZA Y LA CULTURA}

Los antepasados salvajes de los actuales caballos domésticos, Equus caballus, fueron evolucionando en el que habría de ser, pasado el tiempo, el hemisferio occidental, y, desde allí, se dispersaron hacia las demás partes del mundo. En el oeste de Asia y Europa se desarrollaron al menos tres tipos de Equus: el caballo asiático, el tarpán y el diluvial o caballo de los bosques (Edwards 1995: 7-8). De ellos, sólo ha pervivido un tipo de caballo asiático llamado przewalski. Todo indica que la primera domesticación de caballos debió producirse hace unos cinco o seis mil años en el suroeste de Asia (Duncan 1992: 212). Desde allí esta práctica se extendió hasta Egipto 1.500 años a.C., hacia la China unos 1.300 años a.C. y hasta Europa 1.000 años a.C. (Kirkpatrick 1994: 33). Paradójicamente, los caballos salvajes terminarían extinguiéndose hace entre ocho y diez mil años en América, su continente nativo. Sus descendientes, ya domesticados, regresarían al Nuevo Mundo en 1493 con el segundo viaje de Colón (Worcester 1986).

Hoy en día no hay caballos salvajes, salvo que consideremos como tales a los pocos pzrewalski que quedan: unos mil ejemplares distribuidos por distintos zoológicos del mundo, todos ellos emparentados con sólo trece caballos capturados hace algunas décadas. En Uzbekistán (Pereladova et al. 1999) y en Mongolia (FAO 1986) se vienen desarrollando algunos programas para reintroducirlos en las estepas pero no está resultando fácil (Boyd y Houpt 1994). Calificarlos de "salvajes" sería, en todo caso, exagerado, dado el grado de manipulación a que se ven sometidos.

En la actualidad, más que de caballos salvajes (wild horses) sería más ajustado hablar de cimarrones, caballos domésticos que se han asilvestrado por haber sido abandonados o haber escapado de la tutela de sus amos (feral horses). Si algo identifica a estos caballos es esa ambigua condición que les permite moverse, metafórica pero también literalmente hablando, entre la naturaleza y la cultura. En ese dinámico y liminal estatus reside su atractivo y su fuerte simbolismo.

Hay poblaciones que han perdido todo contacto con el hombre y viven en estado salvaje. Hay otras, en cambio, que son escrupulosamente vigiladas, reciben cuidados sanitarios y hasta alimentación suplementaria. En muchos casos, se les aplican acciones selectivas para reducir su número 
o bien para mejorar las características biológicas de las nuevas generaciones, eliminando un cierto porcentaje de ejemplares o introduciendo sementales y yeguas reproductoras de calidad. Es curioso, y en parte irónico, que el volumen de caballos modernos que hoy vive en estado asilvestrado supere ampliamente al de todos los individuos juntos de las otras seis especies de équidos salvajes que hay en el mundo, y que su distribución sea mucho más extensa, hasta el punto de estar presentes en todos los continentes habitados por el hombre (Kirpatrick 1994: 43). Encontramos poblaciones de estos caballos en lugares tan distintos como las Marismas de la Camarga francesa, la Isla de Sable en el Atlántico norte, el desierto de Namibia en el sur de África, las islas Abaco de las Bahamas, la región brasileña del Serrado, el Cabo Toi de Japón o la Sierra de Kaimanawa de Nueva Zelanda.

Por desgracia, esta excelente adaptabilidad no ha impedido que las grandes poblaciones de antaño, como las que pastaban en Estados Unidos y Argentina, se hayan visto enormemente mermadas durante el siglo xx. Sólo en Australia han pervivido algunas manadas de cierta entidad que suman en conjunto entre 300.000 y 600.000 individuos (Dobbie et al. 1994; Kirkpatrick 1994: 63). Pero incluso estos caballos australianos sufren la presión humana y se ven regularmente castigados por condiciones ambientales muy duras. Es lógico que, a causa de su posición intersticial entre la naturaleza y la cultura, la fortuna de estos y otros caballos asilvestrados dependa de las distintas y variables relaciones que en cada caso las comunidades humanas establezcan con su medio.

En términos generales, se puede achacar al demoledor avance de la modernización, del hombre y sus intereses, esta abrumadora disminución de las poblaciones en los últimos cien años. Sus antiguos hábitats han dejado de ser marginales y se han visto progresivamente vallados. A veces, los ganaderos los rechazan por su competencia con el ganado doméstico por los mismos recursos alimenticios. Otras, son los conservacionistas quienes se quejan de su impacto sobre la vegetación de un determinado ecosistema, como ha sucedido en Kaimanawa (Nueva Zelanda) y también en el Parque Nacional de Doñana. Además, la mecanización del campo ha hecho que pierda sentido conservarlos como potencial fuerza de trabajo agrícola. Muchos de ellos han acabado siendo explotados como comida para animales o para personas, lo que, en casos, ha propiciado su extinción. También, desdichadamente, la caza indiscriminada ha contribuido a este declive imparable de la mayoría de las poblaciones.

La influencia del turismo en la evolución de sus efectivos es igualmente destacable, aunque no siempre negativa. Duncan (1992: 217), por ejemplo, atribuye la recuperación de los caballos blancos en la Camarga 
francesa desde 1948 a haberse convertido en un atractivo para la industria turística. Para protegerlos, se les ha venido proporcionando alimentación complementaria durante el invierno y una buena atención veterinaria. En otros casos, el turismo sólo les ha acarreado problemas, como ha ocurrido en la barrera de islas entre Georgia y Maryland, en la costa oriental de los Estados Unidos. Éstas, que fueron una vez tierras aisladas en las que los caballos habían vivido libremente durante siglos, son hoy un preciado destino vacacional. Ante la avalancha de turistas, los residentes locales decidieron organizarse para salvar sus tradiciones con estos caballos, pero no pudieron evitar que buen número de ellos cayera víctima de atropellos de coches (Brown 1992).

La organización social de los caballos asilvestrados, como explica Miller (1986), sigue un canon típico que es similar al de las cebras de las sabanas: un semental encabezando un grupo de hembras con sus crías (Klingel 1974). McCort (1984: 494-495) cita otras dos modalidades de agrupamiento también relativamente típicas: los grupos con varios machos y varias hembras, y los grupos de machos sin hembras (bachelor males). Y añade, basándose en otros estudiosos del tema (sobre todo, Miller y Denniston 1979), que sólo algunas poblaciones de caballos silvestres en el mundo pueden ser consideradas manadas en sentido estricto, o sea, grandes agrupaciones en las que están presentes estos tres modelos asociativos. Obviamente, las características y el grado de estabilidad de la organización social de estos équidos varía mucho de un caso a otro (Coates-Markle 1997), entre otras razones, por el particular modelo manejo que se les aplica.

Por regla general, cuando los caballos cimarrones viven en soledad y encuentran las condiciones ecológicas apropiadas, se vuelven extraordinariamente fértiles. Se sabe que, antiguamente, llegaron a constituir poblaciones espectaculares en las pampas de Suramérica (Nichols 1939), en las llanuras de los Estados Unidos (Wyman 1945) y en los territorios del norte de Australia (McKnight 1976). Ahora bien, cuando la civilización y los intereses comerciales ponen sus ojos en sus áreas de pasto, su mengua no tarda en producirse hasta desembocar incluso en su total liquidación. Por fortuna, menudean las iniciativas para, con acciones muy diversas y siempre con mucha perseverancia, mantener sus efectivos y también, a veces, para mejorar sus cualidades biológicas. A lo largo del tiempo, se han ido creando cientos de grupos y asociaciones en distintos países con el encomiable objetivo de salvar las últimas poblaciones que aún quedan en el planeta. 


\section{Los mustangs de Norteamérica y los PONIS DE la GRAN BRETAÑA: DOS} CASOS PARA UN ANÁLISIS COMPARATIVO

Como ya hemos dicho, el trato aplicado por el hombre a los caballos asilvestrados, allí donde los hay o ha habido, revela, de algún modo, la particular actitud que un determinado grupo humano tiene ante la naturaleza. El variable manejo de que son objeto estos caballos, y no su presunta singularidad racial, es precisamente la clave para entender su identidad liminal, y lo que marca su excepcional relación con la cultura. Para ahondar en este argumento, vamos a abordar de manera comparada dos ejemplos clásicos: los mustangs norteamericanos y los ponis británicos.

Quizás por su importancia cuantitativa (se calcula que quedan entre cuarenta y cincuenta mil ejemplares), pero más que nada por su estelar presencia en las películas del Oeste, los mustangs norteamericanos son, sin lugar a dudas, los caballos asilvestrados más famosos y emblemáticos del mundo. Su gran significación, como símbolos de una vida en libertad, tiene que ver con el hecho de que, al menos hasta hace poco, quedaban algunas poblaciones escasamente intervenidas por el hombre.

Es de suponer que los grupos iniciales de mustangs se formaron con descendientes de los primeros caballos que llegaron con los españoles a América. Su mismo nombre, mustang, es un derivado de "mesteño", "mestenco" o "mostrenco", un término que hace mención a animales sin dueño conocido, asilvestrados y cerriles (Worcester 1986: 1). Con el tiempo, nuevas variedades de caballos, traídos por sucesivas oleadas de colonos europeos, fueron integrándose en estos grupos primitivos, enriqueciendo su diversidad. Sigue habiendo, no obstante, una cierta controversia sobre si ha persistido o no, y hasta qué extremo, la conexión genética entre aquellos primeros ejemplares venidos de España y los actuales mustangs (Zarn y otros 1977: 2). En nuestra opinión, tal disputa es, a estas alturas, irrelevante. Todos los expertos coinciden en señalar que ha habido un intenso proceso de mestizaje. En cinco siglos, es imposible calcular la cantidad, pero seguramente han sido muchos los animales domésticos que, de una u otra manera, se evadieron de sus corrales y fueron integrándose en las manadas silvestres. Es justamente esta circunstancia etológica, vivir al margen del hombre, la que identifica verdadera y esencialmente a estos caballos y no la dudosa pureza racial de su dotación genética. Pero lo que, sobre todo, aumenta su atractivo y singularidad es la ambivalencia que supone su capacidad de moverse, con admirable adaptación, en los dos sentidos del continuum cultura/naturaleza. Infinidad de historias, trufadas de romanticismo, relatan el regreso voluntario 
de algunos mustangs a sus viejos corrales después de muchos años de ausencia, y, a la inversa, su repentina huida hacia la libertad, tras haber vivido entre hombres largo tiempo.

El crecimiento de las poblaciones de mustangs desde los momentos mismos de la colonización española fue espectacular. Desde el norte de México fueron extendiéndose hacia los actuales Estados Unidos, hasta alcanzar, según McKnight (1959), sólo en el oeste de este país, los cinco millones de individuos a fines del siglo XvII. Tal volumen de animales sólo era quizás superado, en ese momento, por el de los búfalos de las praderas. En 1900, esa cifra se había reducido hasta los dos millones. Desde entonces su número no dejó de caer en picado (a fines de los sesenta sólo quedaban 17.000), hasta que en 1971, gracias a leyes federales, empezó su protección y con ella su relativa recuperación, como resultado de una protesta de escolares sobre la triste situación de unos animales tan simbólicos que, desde los años veinte, estaban siendo sacrificados para convertirse en comida para gatos, perros y pollos. Con esta legislación, aplaudida por la opinión publica, se iniciaba una nueva etapa en la que un organismo de la administración norteamericana se encargaría de vigilar a los mustangs en tierras federales. A esta iniciativa se unieron decenas de asociaciones privadas, entre las que destacan la Spanish Mustang Registry, la National Mustang Association, la American Mustang Association y la Spanish Barb Breeders Association, en las que, como se observa, la referencia española es un signo distintivo ${ }^{3}$. Los objetivos de estas asociaciones no son idénticos. Las hay que pretenden recuperar la presunta pureza biológica de los caballos; otras se ocupan de proteger sus hábitats naturales y/o controlar sus efectivos para favorecer su sostenibilidad; otras, en fin, se oponen a cualquier tipo de intromisión y limitación en la evolución de las poblaciones.

Los mustangs, si exceptuamos algún caso aislado (por ejemplo, el de los ponis de Cincoteague en Virgina), suelen ser de propiedad federal. Para regular su número sin recurrir al sacrificio, las autoridades venden ejemplares (en realidad, hablan de "adopción") a bajo precio a particulares. Cuando esto sucede, es decir, cuando un caballo asilvestrado pasa a manos privadas, pierde su condición de mustang, no sólo por su previsible domesticación, sino por haber dejado de vivir libremente. 'Los mustangs

\footnotetext{
${ }^{3}$ Otra prueba elocuente de la importancia concedida a estos lazos históricos es la revista especializada Conquistador. The World of Spanish Horses (Amigo Publications, Solvang, California), con una trayectoria ya de diez años. Véase su página web (http:L $\angle$ www.conquistador.com) en la que pueden encontrarse referencias bibliográficas, enlaces y direcciones de interés.
} 
son, para los americanos, uno de sus iconos nacionales y uno de sus símbolos de la libertad, referencia esencial de su autodefinición como comunidad política (Dobie 1934), lo que, sin embargo, no ha frenado su imparable declive a lo largo del siglo xx. Son también, por esta razón, el símbolo nostálgico de una naturaleza salvaje perdida y definitivamente hollada por la civilización ${ }^{4}$ (Bilger 1991: 13).

También los ingleses sienten por sus caballos asilvestrados un gran orgullo al haber logrado, con empeño y dedicación, mantener sus nueve razas de ponis ${ }^{5}$, como la de New Forest, que será la que nos servirá de referencia comparativa con las yeguas marismeñas. A diferencia de los mustangs, que basan su identidad más preciada en una vida libre lejos del hombre, los ponis, que, en principio, son también caballos cimarrones, reciben constantes cuidados y un seguimiento escrupuloso por parte de sus dueños a fin de garantizar su pervivencia racial diferenciada.

Los mustangs, como hemos relatado antes, guardan un indudable vínculo con los primeros caballos españoles llegados a América. Sobre los ponis también se ha difundido la leyenda de una relación histórica con caballos procedentes de España, acaso para ennoblecer su origen. Esta suposición nace de una narración popular, una "bonita historia", como dice T. F. Sheaf (1903: 417), que sitúa su origen en el desastre de la Armada Invencible enviada por Felipe II en 1588 contra los ingleses. Recuérdese - curiosa coincidencia- que el almirante de esta flota era también el entonces propietario del Coto de Doña Ana (después Doñana), el Duque de Medina Sidonia. Pues bien, según esta historia, en medio del fragor del combate y las tormentas, uno de los barcos de la escuadra española, que llevaba a bordo caballos, derivó su rumbo hasta las costas escocesas, y, por fin, naufragó. Los caballos lograron ganar a nado la península de Galloway y, en poco tiempo, se adaptaron a este lugar solitario y agreste. Y pronto, por todo el país corrió su fama de caballos veloces, robustos y

\footnotetext{
${ }^{4}$ Éste es precisamente el eje argumental de la película de John Huston The Misfits (Vidas rebeldes, 1961), con guión de Arthur Miller. Los protagonistas (interpretados por Clark Gable y Montgomery Clift) son dos cowboys que pretenden prolongar un modo de vida que ya ha pasado irremediablemente. Para ello deciden capturar mustangs, valiéndose de su destreza como vaqueros experimentados, pero, irónicamente, para que se conviertan en comida para animales domésticos. Finalmente, cuando se aproxima el sacrifico de los caballos, deciden soltarlos para que se libren de un fin tan innoble. Con este gesto postrero queda dolorosamente subrayado, tanto para estos hombres como para estos caballos, un destino en el que la libertad se ha vuelto una quimera.

${ }^{5}$ Los ponis de Exmoor, Dartmoor, Welsh, Connomara, Dale, Fell, Highland, Shetland, y, por supuesto, los de New Forest.
} 
resistentes. Algunos de los descendientes de estos primeros ponis de Galloway fueron trasladados a otros lugares de las Islas Británicas y se mezclaron con caballos locales. Pasado el tiempo, de estas mezclas surgieron las diversas razas de ponis que hoy conocemos. Entre ellas, la de los ponis de New Forest.

En realidad, no se conoce con absoluta fiabilidad cuál es el origen de los ponis británicos, pero la mayor parte de los expertos opina que provienen de caballos nativos. Si en ellos hay rastros de sangre española, y puede que así sea, es puramente casual. Creen que la especie evolucionó en condiciones de gran aislamiento después de que las Islas se separaran del continente europeo (Edwards 1992: 29) y que, sólo mas tarde, los caballos autóctonos se cruzarían con los que trajeron los conquistadores escandinavos y los romanos. A diferencia de los mustangs, los criadores ingleses no han cejado en su empeño de intervenir en la vida de sus ponis para conservar los rasgos que identifican cada una de sus razas: su altura, capa y constitución física general. Tal interés ha propiciado la proliferación de asociaciones en defensa de los ponis y la elaboración de registros pormenorizados de la genealogía de cada ejemplar.

La mayoría de las nueve razas a las que hemos aludido se refugia ahora en las regiones más inaccesibles e inhóspitas del país (montañas, páramos, marjales), como se deduce de este otro nombre Mountain and Moorland Ponies (Grayson 1998) con el que se les conoce. Los ponis de New Forest, en cambio, siguen ocupando sus tierras tradicionales, en el espacio más extenso ( 144 millas cuadradas) que aún permanece libre y en manos públicas en el Sur de Inglaterra (suroeste de Hampshire).

Todo indica que hace al menos mil años ya estaban allí estos ponis. El rey Guillermo II el Rojo convirtió las tierras de New Forest (donde precisamente moriría en agosto del 1100) en un coto real de caza al que se aplicó una estricta regulación jurídica y una meticulosa vigilancia contra las prácticas furtivas (Grayson 1998: 51). Sin embargo, los derechos de los vecinos sobre el uso de los pastos comunales fueron respetados. Desde entonces, esta ventaja ha prevalecido, de manera que sólo los "comunes", es decir, los propietarios de fincas de los alrededores o sus arredantarios gozan del derecho a que su ganado, sean vacas o caballos, paste en New Forest, a pesar de los cambios históricos operados en esta región británica (Edwards 1992: 28). Para conservar ese privilegio, los dueños están obligados a pagar unas tasas, de las que queda constancia por el insólito sistema de hacer un corte particular en la cola de los animales de su propiedad. Salvando las distancias y las particularidades de cada caso, saltan a la vista las coincidencias con algunos aspectos sobresalientes de la historia de Doñana desde que fuera acotado para cazadero real a fines del siglo XIII. 
Mientras duró su estatus de coto, los ponis debían abandonar New Forest durante la mitad del año, para evitar su competencia con los ciervos por los mismos pastos (Pollock 1980: 6). Los ganaderos se veían entonces obligados a recoger sus animales y alimentarlos cinco o seis meses en sus propios establos y corrales, lo que contribuyó a un severo descenso del número de cabezas (Tyler 1972: 88). A partir de 1851, esta situación dio un giro sustancial gracias a unas normas (Deer Removal Act) destinadas a la eliminación de los ciervos para proceder a la reforestación de la zona. Los ponis se vieron beneficiados y su número aumentó hasta la cifra de unos 3600 individuos en 1980 (Pollock 1980).

En la actualidad, los ponis viven en el campo, sobre todo las hembras, durante todo el año. En Septiembre, se celebra un rodeo (drift) para realizar un censo con fines impositivos, aplicarles las medidas veterinarias necesarias o venderlos, sobre todo si son machos. Éstos representan sólo un $5 \%$ del total y sufren periódicos traslados dentro del "bosque" para evitar en lo posible los cruces consanguíneos. Si sus características raciales no son óptimas pueden incluso llegar a ser descalificados como ponis y expulsados de New Forest.

Desde fines del siglo XIX, los propietarios (Commoners) han tenido su propia representación legal, una especie de tribunal (Court of Verderers) encargado de administrar las tierras de pasto, de vigilar y mejorar la calidad del ganado. Se vale para ello de un servicio de guardas (The Agisters) que controlan las operaciones cotidianas con los animales. Son los encargados de expulsar a los caballos racialmente inadecuados, cobrar las tasas, organizar los rodeos y evitar los frecuentes atropellos de animales (Edwards 1992: 29; Tyler 1972: 87).

Desde 1970 aproximadamente, la media de ponis por propietario ha ido descendiendo. La mayoría de ellos posee menos de diez ejemplares. Tal ratio indica que la cría de estos caballos es ahora una actividad más recreativa que económica (Kiff 1972, cit. por Pollock 1980: 12), como también sucede desde hace tiempo en Doñana. Los rodeos (Drifts) se han convertido, y éste es otro paralelo con la cría de yeguas en las Marismas, en la actividad más importante que se celebra durante el año en New Forest, y la más esperada por los criadores de ponis y por los turistas, que acuden en cantidad a ver el espectáculo (Edwards 1992: 36). Aunque su organización depende de los guardas, en realidad son los mismos ganaderos los verdaderos protagonistas de este evento festivo. Son ellos quienes marcan los potros nuevos, cortan las colas de los ponis que han satisfecho sus cuotas y realizan las operaciones de compra-venta. Se sabe que antes también solían acudir a este mercado de caballos algunos grupos de gitanos (Sheaf 1903). 
Aunque sean vendidos y abandonen los pastos de New Forest, los ponis no pierden su condición de tales, a diferencia de lo que les sucede a los mustangs americanos. Hay ponis registrados en fincas privadas de muchos lugares de las Islas Británicas e incluso en otros sitios del mundo. A pesar de ello, mantienen su identidad racial como poni, incluso sin haber vivido libremente en ningún momento de su vida. En este sentido, estos caballos ocuparían el polo opuesto, el de la máxima intervención humana, al que ocupan los mustangs, el de la menor, en este mundo tan proteico de los caballos asilvestrados.

Entre estos dos polos, hay una cambiante gama de situaciones intermedias. A mitad de camino, se encontrarían las yeguas que viven en las Marismas del Guadalquivir. Actualmente, como tendremos ocasión de ver con más detalle, en su crianza se aprecian indicios de una progresiva institucionalización que probablemente acentuará su manejo por el hombre y su mayor integración en la vida cultural local. En cualquier caso, las yeguas de Doñana no han llegado, y tal vez nunca lleguen, a un sistema de control y registro biológico exhaustivo como el que se observa en los ponis, pero además, y ésta es una diferencia aún más significativa, su identidad está basada más en su vinculación con un hábitat concreto que en su caracterización morfológica. En las narraciones populares sobre caballos marismeños, hay una constante: la irrefrenable tendencia de estos animales a volver al sitio donde han nacido o vivido, a su querencia.

\section{LAS YEGUAS DE LAS MARISMAS DEL GUADALQUIVIR}

[...] los caballos casi salvajes de las Marismas [...] que sobreviven sin ayuda de nadie todo el año por esas vastas llanuras y huyen, como gamos, ante la rara presencia del hombre. Ni el calor del verano, ni el frío ni la humedad del invierno, desalientan a esta recia raza que, en recompensa por su vida libre, regala a sus propietarios un contingente anual de robustos potros. Con gran dificultad, y tras largas y veloces carreras por estos llanos abiertos, los ganaderos separan, rodean y capturan sólo a los potros. Al verse atrapados, se vuelven verdaderos diablillos tercos y enfurecidos [...] con su piel peluda desordenada, cubierta de lodo seco, mordiéndose entre sí, peleando y chillando con rabia salvaje —verlos en el corral, recién capturados, es, sin duda, una imagen insólita- Hay viejas yeguas de la Marisma a las que nunca el hombre ha llegado a ponerles un cabestro $^{6}$ (Chapman y Buck 1893: 234).

Estos caballos "casi salvajes", descritos tan expresivamente por los cazadores-naturalistas ingleses A. Chapman y G. Buck a fines del siglo XIX,

${ }^{6}$ Texto traducido por los autores. Para otras descripciones parecidas, véase también Chapman y Buck (1910: 78) y Verner (1909: 111). 
no han merecido, inexplicablemente, atención alguna en la literatura comparada sobre caballos asilvestrados (feral horses) en el mundo (v.g. Miller 1986; Edwards 1995 y Krautwurst 2000). Ni siquiera los estudios más rigurosos sobre poblaciones específicas dan noticia sobre ellos en sus referencias comparativas (v.g. Tyler 1972; Berger 1986; Duncan 1992 y Kirkpatrick 1994). Y lo que es más sorprendente, tampoco ha habido el menor interés por estudiarlos entre los científicos que se han ocupado de la ecología del Parque Nacional de Doñana. Sólo muy recientemente han aparecido algunos trabajos, sin demasiada continuidad en la mayoría de los casos, que han abordado la ganadería marismeña, pero casi exclusivamente la bovina.

No hay que olvidar que este espacio natural ha generado una ingente cantidad de investigaciones y publicaciones en la segunda mitad del siglo xx (Bernués y Montes 1994) y que un prestigioso instituto científico (la Estación Biológica de Doñana), especializado en zoología de vertebrados, está instalado en la zona desde los años sesenta. Las referencias bibliográficas sobre la etología o la biología de estos caballos son, al día de hoy, escasísimas y anecdóticas, casi siempre para evaluar (y denostar, a veces) su competencia con los herbívoros salvajes de la Marismas. Los caballos (el ganado, en general) están, por ejemplo, completamente ausentes del estudio pionero de J. A. Valverde (1960) sobre la comunidad de vertebrados de Doñana, a pesar de que representaban entonces una población zoológica cuantiosa. Sólo algunos biólogos, en tiempos recientes, han reparado explícitamente en la importancia que la ganadería ha tenido en la historia ecológica del Parque y en la que podría tener para su futura conservación (v.g. Castroviejo 1993; Lazo 1992, 1995 y 1996). Desde el punto de vista de las ciencias sociales apenas han merecido alguna atención. Tiene un gran interés el capítulo que P. Campos y J. López (1998: 79-103) dedican a la ganadería, y en particular al ganado caballar, en su excelente estudio sobre la renta económica que generan los recursos naturales en Doñana. Otro material disponible, de gran utilidad por su carácter seriado, lo constituyen los censos realizados por el Parque Nacional y algunos informes de su personal técnico.

Sin duda, a este continuado y general "olvido científico" ha contribuido la perspectiva conservacionista e investigadora dominante durante décadas en el Parque, para la que el ganado asilvestrado era un intruso en la naturaleza y su estatus era, en consecuencia, inferior al de las especies consideradas como plenamente silvestres. Al parecer, ser "casi salvajes" no ha sido suficiente para otorgarles los beneficios de la protección y la investigación como miembros de pleno derecho de la comunidad biótica del Parque Nacional. Lo que no deja de ser históricamente paradójico, por 
cuanto la ganadería es una actividad ancestral en Doñana. Caballos y vacas - sin contar con los toros del legendario rey tartésico Gerión- han precedido en estas tierras a algunas de las especies de su fauna salvaje. Algunos científicos y, por supuesto, muchos marismeños están convencidos, por ejemplo, de que el ganado contribuye a regenerar la vegetación y facilita la viabilidad de determinadas especies orníticas.

Ya el geógrafo e historiador griego Estrabón (63 a.C.-24 d.C.) citó en sus escritos los pastos y las vacas lecheras que habían abundado en las islas del estuario del Guadalquivir en la época tartésica, antes incluso de que se convirtieran en una marisma (Butzer 1988). En época romana, esta región siguió siendo área de pasto para el ganado, uso que alcanzó gran auge durante la larga etapa árabe. En el año 1100, Al-Razi escribe sobre la demanda en el mercado de los excelentes quesos hechos con la leche de las vacas marismeñas, y dice: "Hay aquí islas bajas, marismas y prados que nunca se secan; el ganado da abundante leche; si se juntara todo el ganado de España, aquí hallaría pasto suficiente" (Butzer 1988: 39). Se sabe también por éste y otros autores (Al-Udri, Ibn Hayyan y Al-Himyari, entre ellos) que los árabes criaron caballos y yeguas de vientre para las tropas califales en Al-Mada'in (las Marismas), cuyos recursos eran explotados y controlados normalmente desde Sevilla, salvo cuando lo fueron desde la misma Córdoba por su valor estratégico para el califato (Roldán Castro 1997).

Igualmente sabemos que, en la Baja Edad Media, las Marismas quedaron al margen de las grandes apropiaciones de tierra tras el repartimiento cristiano, a causa de su salinidad, su morbilidad, sus ciclos anuales de inundación y su consecuente inutilidad para la agricultura. Por eso, mientras las tierras cultivables eran concienzudamente subdivididas y su estatus jurídico quedaba rigurosamente establecido, vastas zonas marismeñas de pasto permanecieron bajo dominio público, siendo regulado su uso paulatinamente (Carmona Ruiz 1998: 113). En las Marismas del Guadalquivir la pervivencia de regímenes de propiedad comunal y municipal permitiría un acceso más libre a los vecinos de las poblaciones próximas y a los rebaños trashumantes que venían del norte, en contraste con lo que iría sucediendo en el Coto, convertido, después de haber sido cazadero real, en una finca señorial también dedicada a la caza. Esta cita de 1583 (Cruz 1908: 14) da cuenta de los derechos populares sobre los pastos marismeños, reconocidos por el propio Duque, que, sin embargo, se reservaba para sí los recursos más valiosos del Coto:

Al Excmo Sr Duque de Alba y Medina Sidonia corresponden las alcabalas de esta Villa, derechos de saca y portazgo, penas de cámara, la jurisdicción que nada 
produce, tres dehesas, bellota, caza y demás que contiene el Coto de Doñana á ecepción de las yerbas de la Marisma...

Por otro lado, los acuerdos y hermandades de pasto, caso de la establecida entre los Concejos de Hinojos y Almonte (Ojeda 1987: 47; Carmona Ruiz 1998), contribuyeron también a facilitar a los vecinos de los pueblos el pastoreo en esas zonas lacustres que constituían una plausible alternativa ante la insuficiencia de las dehesas comunales $u$ otras áreas de pasto.

En torno a 1500 , cuando las Marismas se extendían aún a una y otra orilla del río, la actividad ganadera, adaptada a su régimen estacional de riadas, era ya destacable. Todo su contorno y algunas zonas interiores estaban salpicados de estancias, haciendas, ranchos y hatos, denominaciones locales que después se reproducirían en América ${ }^{7}$ (Butzer 1988: 49). A las Marismas llegaban los rebaños de la Mesta y las piaras de cerdos, ovejas, cabras, vacas y caballos de los ganaderos de las localidades próximas, que, en esos años, habían crecido en población y, por ende, aumentado sus demandas de tierras de pasto. Un laberinto de veredas y cañadas prueba que los movimientos del ganado entre las dehesas y el monte y las marismas, cuando éstas se iban anegando, eran comunes en esos momentos en esta región. Ya entonces el ganado se asilvestraba a causa del mucho tiempo que pasaba en soledad lejos de sus guardas o propietarios y no se le podía estabular con facilidad, como recordarían a su Ayuntamiento los ganaderos de Almonte en una carta de 1853, pidiéndole permiso para que su ganado marismeño pastase en los olivares del ruedo agrario mientras duraba una larga sequía. En ella podemos además leer una curiosa descripción "etológica" sobre el carácter "cerril e indómito" de estos animales, muy similar a la de Chapman y no muy lejana de las imágenes que narran las historias populares sobre los mustangs americanos:

Sabido es que Almonte tiene hoy una riqueza considerable en su ganadería y que la que pertenece a la clase de yeguar, caballar y de cerda tiene su crianza y pastage [sic] casi en todo el año en las Marismas de su término, y que por esta circunstancia es todo cerril e indómito, motivo por el que no pueden encerrase en establo [...] Y que no gozando el aire libre o la libertad a que están acostumbrados, se exponen a sufrir muertes repentinas y otros padecimientos incurables, por la sofocación que experimentan estando encerrados" (Álvarez Gastón 1978: 52).

\footnotetext{
7 Una de las palabras más definitorias del manejo de los caballos de la Marisma, la tusa (el corte de crines y cola) es una prueba fehaciente de los préstamos léxicos de la ganadería marismeña a la del Nuevo Mundo. Tanto es así que este término se ha vuelto raro en nuestro país y en el DRAE aparece ahora como una voz preferentemente americana. Véase Adams (1945).
} 
Del entorno de las Marismas salieron cientos de emigrantes en los primeros años de la colonización americana. Con ellos también "emigró" el ganado. Como escribe Butzer (1988: 52):

El grupo pionero de la futura cabaña hispanoamericana fue embarcado hacia las Indias Occidentales desde Sevilla, Sanlúcar, Cádiz y Palos en un espacio de tiempo muy corto (1493-1512); en esos años debieron viajar como mínimo unas 500 cabezas (Rouse, 1977). Todo indica que, a causa de su procedencia marismeña, el ganado fue presumiblemente vigilado y atendido a bordo por vaqueros de esa región. Nada tiene de extraño que la llegada del primer ganado a Santo Domingo corriera a cargo de una docena de pastores, de dudosa honorabilidad, venidos del estuario del Guadalquivir.

Esta inicial importación de ganado se dejará notar claramente en Nueva España, donde pronto los usos ganaderos remedarán el modelo marismeño, único en España por su extraordinaria adaptación ecológica a las condiciones climatológicas del trópico. Disponemos de algunos estudios de historiadores y geógrafos norteamericanos (v.g. Bishko 1952; Butzer 1988; Jordan 1989 y 1993), que se ocupan, justamente, de la transferencia del modelo de manejo del ganado en las Marismas del Guadalquivir a zonas de América del Sur y Norteamérica ecológicamente comparables. Por esa indudable funcionalidad, también entre los ganaderos emigrados oriundos de otras regiones españolas, prosperó el peculiar estilo de manejo traído desde las marismas andaluzas. A este respecto escribe Doolittle (1987: 9):

Ecológicamente, las Marismas vienen a ser como el corazón de la cría en libertad del ganado en la Península Ibérica, sistema que empieza a implantarse en el área mexicana de Pánuco y que alcanza su cénit en Texas. Los datos migratorios avalan esta hipótesis [...] Éstos indican que una significativa proporción, entre el 25 y el 30 por ciento, de los colonizadores de Pánuco en el siglo XVI procedían de zonas próximas a las Marismas de la costa atlántica andaluza. Al menos, el 22 por ciento de esos primeros emigrados venían directamente de pueblos cercanos a las Marismas del Guadalquivir.

Tal como ocurrió con las costumbres ganaderas de las planicies interiores de Extremadura y Castilla, que fueron adoptadas en las mesetas y pampas americanas, así aconteció con la guarnición de los caballos de los vaqueros marismeños, la conducción del ganado con garrocha, sus traslados estacionales, incluso el sistema legal de uso de los pastos y la mayor parte de topónimos ganaderos de las Marismas, que también fueron transplantados, como ya dijimos, a áreas de América con cierta similitud ecológica. En palabras de Terry Jordan (1989: 120), "el sistema ganadero de las Marismas andaluzas representó una singular y viable adaptación a un medio único". 
El proceso de difusión al Nuevo Mundo de estas producciones culturales de los ganaderos marismeños es de un valor histórico-ecológico incalculable. La ganadería de las Marismas del Guadalquivir representa, sin lugar a dudas, la matriz cultural de las tradiciones ganaderas que se desarrollan en América a partir del siglo XVI, tras los viajes colombinos. Es obvio que, en cada una de ellas, se han producido reelaboraciones culturales específicas y trayectorias sociales peculiares. Pero, aun contando con estas importantes diferencias, el gaucho argentino, el huaso chileno, el llanero venezolano, el charro mexicano y el cowboy de los Estados Unidos o del Canadá comparten, cada uno a su manera, una herencia común andaluza y, más concretamente, marismeña (Bennet 1998).

Es, insistimos, incomprensible que una actividad, como la cría de caballos asilvestrados, de tan larga tradición en las Marismas de Doñana, pero, sobre todo, tan crucial para el desarrollo de la ganadería americana, no haya merecido la atención científica apropiada, ni siquiera un espacio relevante en la información turística que producen las agencias del Parque. Cabe esperar que en el futuro este vacío irá desapareciendo con el concurso del nuevo Plan Ganadero que, con un laborioso acuerdo entre ganaderos y gestores del Parque Nacional, se aprobó a comienzos de 2001. Es ésta una norma sin precedentes en la historia de esta actividad en la Doñana contemporánea. Precisamente, el capítulo IX de este Plan, dedicado a la investigación, reconoce las graves carencias informativas sobre la ganadería en el Parque, la necesidad de su estudio interdisciplinar y el implemento de investigaciones sobre sus valores culturales, demás de su impacto en el medio, las condiciones biogenéticas y la etología del ganado.

Por ahora, como anteriormente dijimos, no disponemos de estudios etológicos reseñables, pero, a pesar de ello, sabemos que los caballos y yeguas que viven en libertad en las Marismas del Guadalquivir se ajustan al modelo de organización social más habitual entre los équidos asilvestrados, el modelo del "harén". Es decir, asociaciones de tropas de yeguas y potros bajo la autoridad de un semental (Murphy 1987; Márquez Guitart 1998; González Faraco y Murphy 1999a). Es interesante indicar que los ganaderos limitan el número de machos, vendiéndolos para uno u otro fin según su calidad, mientras suelen conservar a la mayoría de las hembras reproductoras. Ésa es la razón por la que, más que de caballos, se suela hablar de yeguas (representan un $75 \%$ de la cabaña) y a sus criadores se les llame "yegüerizos" (González Faraco 1991b).

El número de estos animales ha ido ascendiendo levemente desde comienzos de la década de 1980, cuando había poco más de 600 individuos, hasta rondar los 1000 como media en la última década (1991-2001). Actualmente, se eleva a los 1200-1400 ejemplares pastantes en los dos 
momentos óptimos del año, fines de la primavera y comienzos del otoño. Éstos viven desigualmente dispersos por sus querencias o careos de las diversas fincas del Parque, salvo en las reservas dirigidas por el Consejo Superior de Investigaciones Científicas. En ellas sólo pasta ahora ganado de propiedad pública (unas 300 cabezas, entre vacas y yeguas) que está sometido desde hace algún tiempo a un cierto control de pureza biológi$\mathrm{Ca}^{8}$. En el resto, la propiedad del ganado es privada. A los responsables de la conservación del Parque, no sólo les preocupa la cantidad de ganado pastante (creciente y significativamente superior en el caso de las vacas $^{9}$ y relativamente estable en el de los caballos) y su estado sanitario, sino sobre todo el rápido incremento de propietarios. Si tomamos como referencia las cifras de 1991 de la Asociación de Criadores, vemos que una década después su número se ha duplicado (puede estar en torno

\footnotetext{
${ }^{8}$ Hay quienes afirman que, aunque no estamos ante una subespecie ni tan siquiera ante una raza específica, las yeguas marismeñas reúnen una serie de rasgos morfológicos adaptados a su ecosistema (por ejemplo, el casco más ancho de lo normal), además de ciertas cualidades comportamentales propias de su vida asilvestrada (como su fuerte apego al sitio donde han nacido). Como los cruces han sido muy frecuentes, sólo cierto tipo de yeguas representa, en opinión de los ganaderos más avezados e incluso de algunos científicos (Castroviejo 1993), este impreciso modelo marismeño. Las identifican con un lugar concreto, La Retuerta, situado en la vera entre la marisma y el monte, conocido por su densa vegetación, casi selvática. Se asegura que aún quedan ejemplares que la Estación Biológica (CSIC) quiere conservar como un pool genético, a partir del cual pueda regenerarse el conjunto de la cabaña. Los caballos de la Retuerta, más asilvestrados y ariscos que la media de la población, serían, pues, la expresión más genuina del ganado caballar considerado "autóctono". Por supuesto, no hay estudios fiables que prueben la validez de estas afirmaciones sobre las cualidades raciales de éstas u otras yeguas marismeñas. En realidad, estamos ante una construcción cultural sólo relativamente compartida.

${ }^{9}$ En el Parque Nacional de Doñana (las cifras varían según las fuentes y cambian a lo largo del año) pastan unas 4.000 cabezas de ganado mayor (vacas y yeguas), además de unas 700 ovejas (datos de la primavera de 2001). El grupo ganadero mayoritario es el que representa la Asociación de Criadores de Almonte (con sus 3.2003.400 cabezas, entre vacas y yeguas). La razón del incremento del número de vacas en los últimos años reside en las subvenciones que los propietarios de éste y otros tipos de ganado autóctono reciben de la Unión Europea. En la actualidad, al menos en este grupo de ganaderos almonteños, se han invertido las proporciones de hace diez años, y probablemente el número de vacas mostrencas (unas 2.000) ahora casi duplica al de yeguas (unas 1.200). Tal disparidad está planteando un nuevo escenario de relaciones internas entre los mismos ganaderos (yegüerizos y/o vaqueros), que ahora pueden o no compartir intereses, si se decantan claramente por la crianza de uno u otro tipo de ganado. El papel económico de las yeguas es insignificante, mientras que el del ganado bovino empieza a ser suficientemente atractivo para quienes han logrado reunir un cierto número de cabezas. Hasta ahora eran contados los ganaderos para los que las vacas representaban un ingreso económico anual significativo.
} 
a $490^{10}$ ), lo que implica un aumento, si no proporcional sí reseñable, de las demandas de entradas en la zona protegida para el manejo del ganado o su vigilancia regular. Ésta ha sido una de las cuestiones que más controversia viene produciendo entre ganaderos y conservacionistas. El nuevo Plan Ganadero prevé una minuciosa regulación por ambas partes de las condiciones de tenencia, control de entradas y extracciones de ganado en las distintas fincas afectadas, con previsión incluso de situaciones excepcionales que, en las Marismas, son relativamente periódicas, sobre todo las causadas por sequías. Este Plan es, a la postre, consecuencia de uno de los más graves conflictos, sobre todo por su resonancia en los medios de comunicación, acaecidos en la reciente historia de Doñana: el intento de invasión en enero de 1993 de un sector del Parque por un grupo de ganaderos de Almonte tras un largo período sin lluvias e infructuosas negociaciones con la Administración de esta reserva ${ }^{11}$.

\section{Los procesos Culturales en torno a los CABallos asilvestrados DE DOÑANA}

Tal como ya comentamos, inmediatamente después de la conquista cristiana a fines del siglo XIII, las tierras arenosas de Doñana ${ }^{12}$, cubiertas de monte y arboleda, empezaron a ser acotadas como cazadero real (Ojeda 1987). En poco tiempo, el cazadero se vio convertido en finca señorial hasta su postrera venta a algunos notables de la burguesía agraria gaditana a fines del siglo XIX. Al convertirse en Parque Nacional en 1969, su historia como espacio reservado y vigilado continuó de una u otra manera, aunque ahora serán empleados del Estado, y no cazadores aristocráticos,

${ }^{10}$ Dato de mayo de 2001. Además, hay que contar con más de un centenar de nuevas solicitudes de ingreso.

11 El Parque Nacional de Doñana tiene una extensión de 50.000 has, de las que unas 27.000 son marismas repartidas entre las provincias de Sevilla y Huelva. Su administración depende de un Organismo Autónomo del Ministerio de Medio Ambiente, aunque desde hace algunos años se tiende a un sistema de cogestión con el gobierno de la Comunidad Autónoma andaluza. La mayor parte de las fincas del Parque son hoy de propiedad pública. Entre ellas destacan las del Consejo Superior de Investigaciones Científicas, singularmente su Reserva Biológica, creada en 1965.

12 Entonces, conocidas por Las Rocinas. Una de las primeras referencias a estas tierras se encuentra en el Libro de la Montería de Alfonso XI (1340-1348). En su relato cita una ermita dedicada a una imagen de la Virgen llamada Santa María de las Rocinas, la misma que en la primera mitad del siglo XVII trocaría este título por el de Ntra. Sra. del Rocío (Murphy y González Faraco 2002b). 
los encargados de impedir o dificultar el acceso a estas tierras a los residentes de las localidades vecinas.

Como igualmente dijimos, las Marismas arrostraron, durante siglos, una imagen de territorio inhóspito, mórbido y de escaso valor, sólo útil para ciertas recolecciones menores y, sobre todo, para la cría de ganado en régimen extensivo. De esas condiciones se derivó su especial estatus jurídico, que facilitaba su uso público y dejaba su control en manos de las comunidades locales, como propiedades comunales, o bien de los concejos municipales, que podían establecer acuerdos de hermandad. Pudieron representar, en consecuencia, una vía de compensación para los vecinos de estos pueblos, que padecían regulares períodos de escasez y se habían visto excluidos de las más apetecibles y saludables tierras del Coto de Doña Ana. Naturalmente, la burla de esta exclusión se convirtió para los más pobres en una forma de vida al margen, basada en prácticas furtivas. Para la mayoría, significó una afrenta y un problema que había que sortear con astucia, bordeando la legalidad o usando tácticas adaptadas a cada ocasión.

En pocas palabras, se puede decir que la organización tradicional de esta área se basó, al menos desde comienzos del siglo XIV, en una desigual división de la propiedad y uso de la tierra que dejaba en manos de una élite las arenas de monte y dehesas, ricas en caza, y el resto, o sea, las marismas, no en su totalidad pero sí en gran parte, para uso ganadero de los pobladores locales o de los rebaños trashumantes. Desde las primeras desecaciones a fines del siglo XIX en la margen izquierda del Guadalquivir y tras las posteriores obras a gran escala en la margen derecha y en el mismo río, la Marisma sufrió una aguda transformación en cuanto a su funcionalidad como ecosistema, en cuanto a su explotación económica y en cuanto a su propiedad (Ojeda 1987: 210-219; González Arteaga 1992; del Moral 1993). Sus zonas naturales se redujeron en un $90 \%$ y en el resto de sus suelos se acometieron profundas intervenciones para cultivos como el arroz.

Al integrarse en el Parque Nacional, las Marismas mejor conservadas, una décima parte de las primitivas, son redefinidas como zona húmeda de alta biodiversidad necesitada de un escrupuloso régimen de protección que regule la presencia humana o incluso la suprima, procurando la paulatina disminución de cualquier actividad extractora de recursos naturales. Este repentino cambio de valor y función de estas tierras, acompañado por la intención de impedir o limitar severamente la presencia de quienes, en número relativamente pequeño, venían desarrollando alguna actividad económica tradicional en un sitio hasta entones tan apartado y marginal, produce, en combinación con otros factores, un efecto contra- 
producente: estimula el interés por participar en algunas de esas actividades tradicionales, como la cría de ganado, en muchos otros que apenas habían tenido antes relación alguna con las Marismas.

A lo largo de cientos de años, algunos grupos de vecinos de las localidades perimarismeñas, y particularmente de Almonte, habían ido perfilando un singular sistema de manejo del ganado que permitiera aprovechar los pastos que ofrecían estas tierras. Siguiendo una bien articulada estrategia de cría extensiva, perfectamente adaptada a sus ciclos ecológicos (Jordan 1993), los ganaderos de Almonte dejan que sus yeguas y sus vacas anden a su aire y sobrevivan por sí mismas en las Marismas, un ambiente hostil que pasa de ser en pocos meses un lago superficial a convertirse en un erial cuarteado. Su interferencia en la vida de los animales es reducida y se concentra, principalmente, en torno a un rodeo anual conocido por la Saca de las Yeguas, en el que la mayoría de los animales, especialmente las hembras y sus potros, es reunida y después trasladada hasta Almonte pocos días antes de la Feria patronal de San Pedro para la tusa, el herrado y la compra-venta (Murphy 1987; González Faraco y Murphy 1999a). La Saca, como otras actividades ganaderas en la Marisma, ha ido evolucionando hasta adquirir una compleja configuración cultural en la que muchos elementos han sido incorporados muy recientemente. Todas estas novedades, más o menos intencionalmente planeadas y ejecutadas, se han revelado muy eficaces para preservar esta actividad pecuaria en momentos de agudo cambio social en estas comunidades y de frecuentes crisis en sus relaciones con la Administración del Parque.

Salvo las rapas das bestas que se celebran en algunos lugares de la Galicia rural (Cabada Castro, 1992) y algunos otros ejemplos en el norte del país ${ }^{13}$, nada parecido a la Saca de las Yeguas de las Marismas de Doñana resta ya en nuestra geografía. Aún no ha amanecido en la Marisma cuando cada 26 de junio los yegüerizos de Almonte, tras pasar una noche al raso entre animados coloquios y evocaciones nostálgicas (Pérez Martínez 1992), alguna que otra copla y más de un trago de vino, desmontan los improvisados y escuetos campamentos instalados en la vera, en las vetas ${ }^{14} \mathrm{y}$ en otros puntos del llano marismeño, y, desde allí, en

${ }^{13}$ Es el caso de los asturcones asturianos. El concejo más relacionado con estos caballos de pequeña alzada, robustos y fieros, es el de Piloña, cuya capital es Infiesto. En su guía se puede leer: "Fiesta del Asturcón. Se celebra en la majada de Espineres, Cordillera del Sueve, en la última quincena de agosto. El momento cumbre lo constituye el marcaje de las crías nacidas durante el último año y la doma de un semental joven".

${ }^{14}$ Franjas de terreno ligeramente elevadas que no suelen inundarse durante las riadas. En esas circunstancias, se convierten en refugio para los animales. 
pequeños grupos, se aprestan para localizar las yeguas que andan dispersas en sus querencias. El laborioso rodeo de los animales pone a prueba la habilidad de los jinetes, que se sirven de una vara de medianas proporciones o chivata para arrearlos. Poco a poco, conforme el sol va ganando altura, se van formando grupos de caballos cada vez más nutridos. Desde el Sur, en las Marismillas o en las Nuevas, o desde la Marisma de Hinojos, jinetes y animales se van encaminando hacia el Norte de la Marisma, entre chapoteos cuando el año ha sido lluvioso y aún quedan charcos en las zonas bajas, o - lo que es más común- levantando una densa polvareda sobre el almajo y la castañuela agostados por el calor de junio.

En ciertos puntos específicos de la Marisma se van congregando las primeras tropas para ir, poco a poco, confluyendo en las playas del Rocío, a la vista de la ermita de la Virgen. Es allí donde se concentra el grueso del ganado y es entonces cuando se termina por decidir - labor que ya en gran parte se ha realizado marisma adentro- qué animales deben seguir viaje hasta Almonte y cuáles deben permanecer en la Marisma. No es tarea sencilla apartar del grupo a aquellos que han de quedarse; el instinto gregario de estos animales es muy fuerte. Las carreras se suceden y la manada, inquieta, se agita y llena el aire de relinchos. Inesperadamente, un caballo que se creía a buen recaudo vuelve al grupo. Se repite la operación y la tranquilidad se quiebra por unos momentos, mientras podemos ver cómo el caballo se aleja jaleado por un jinete desde su montura.

Los yegüerizos, con la cabeza protegida del sol con un pañuelo ajustado bajo la gorra, toman posiciones alrededor de cientos de yeguas que apenas se entrevén en medio de las nubes de polvo. No faltan los comentarios sobre el estado físico de los animales y sobre la calidad de los potricos nacidos en el año. Muchos espectadores se acercan, a prudente distancia, a ver el vibrante espectáculo del rodeo. Hasta hace pocos años, presenciarlo era mucho más difícil, puesto que las operaciones finales se realizaban en el interior de la Marisma de Hinojos y las yeguas, ya seleccionadas, seguían una ruta distante de la Aldea del Rocío para tomar el Camino de los Tarajales y, por fin, llegar a Almonte. Desde hace algunos años, la "Aldea Sagrada" (González Faraco y Murphy 1999b) se ha convertido también en escenario principal de la Saca.

A última hora de la mañana, precedidas por una hilera de yegüerizos, las yeguas entran en las arenosas calles del Rocío y, tras un último agrupamiento, son conducidas al trote hacia el santuario. Allí, desde una de las puertas, abierta de par en par, mientras las yeguas pasan, un sacerdote reza una oración y bendice a jinetes y animales. Se dicen salves y se 
dan vivas a la Virgen, a la que se invoca como Reina de las Marismas y Madre de los Yegüerizos. Terminado este acto, al que asisten muchas personas, las yeguas emprenden viaje, por alguna de las rutas tradicionales, hacia la villa de Almonte, no sin una parada a mitad de trayecto que se aprovecha para un breve sesteo y un agradable refrigerio bajo el pinar, que recuerda, de nuevo, las costumbres de los caminos rocieros.

La entrada por las calles de Almonte es esperada por una muchedumbre que ocupa esquinas y aceras a lo largo de todo el recorrido por el pueblo. La Feria de San Pedro está al caer y el Chaparral, un llano arbolado que sirve de recinto ferial, ya está engalanado con farolillos y luces, y su perímetro ya lo ocupan las casetas. Las yeguas, divididas en tropas de unas decenas de cabezas, van circulando entre la gente, como si el mundo natural de la Marisma se hubiera enseñoreado de las calles del pueblo.

La mayoría de los animales termina en unos corrales, dentro de un recinto ganadero municipal que está a las afueras del casco urbano, donde, al día siguiente, tendrá lugar la tusa: el corte de las crines y las colas para evitar que, de nuevo en la Marisma, su abundante pelo se enrede en las alambradas o en los altos matorrales espinosos. Los potros nuevos, tras una dura pugna por separarlos de sus madres en un corral atestado de yeguas, serán marcados a fuego por sus propietarios, y los niños, en un ritual simbólico de posesión, los montarán por unos instantes.

En los mismos corrales o en la improvisada cantina, construida a semejanza de las casetas populares de la feria, tienen lugar los tratos de compra-venta en un ambiente festivo. No lejos, algunas familias gitanas, como ha sido costumbre en la Feria desde sus inicios, también ponen sus bestias a la vista de todos en un paralelo, y separado, mercado ganadero. No faltan otros alicientes a estas labores que ocupan varios días antes de que las yeguas sean devueltas a la Marisma. Desde hace algunos años, se vienen celebrando concursos morfológicos para premiar la "autenticidad racial" del ganado, en los que viejos yegüerizos y técnicos cualificados clasifican y evalúan, siguiendo un supuesto patrón morfológico óptimo, a aquellas yeguas que optan a los premios. Este empeño por recuperar las señas del ganado marismeño autóctono se une a una variada gama de tácticas culturales, tanto en la Saca como en el conjunto de la cría del ganado, cuyo sentido convergente es el de reforzar su carácter de tradición local, cuando su función económica es ya residual y se acentúa el control de las áreas de pasto por parte de las autoridades conservacionistas. El objetivo no es otro que resistir y enfrentar este proceso de acciones restrictivas sobre la actividad y la misma presencia de los ganaderos almonteños y de los vecinos del pueblo en general, en las Marismas pro- 
tegidas. Esta resistencia, como veremos con más detalle en adelante, ha tomado, en buena parte, como patrón cultural de referencia a los rituales rocieros (Murphy 1987), en los que, como es sabido, juega un papel protagonista el pueblo de Almonte. No es casual que así sea, porque, al menos en los primeros compases de estos procesos, las coincidencias personales entre yegüerizos y rocieros relevantes de Almonte eran muchas.

Una de las primeras medidas tomadas por los ganaderos, en una de las iniciales y más polémicas circunstancias históricas de esta actividad en el Parque, fue crear en 1982 una Asociación de Criadores de Ganado Marismeño, con unos 130 socios fundadores (hoy, como adelantamos, rondan los 500), cuya primordial preocupación sería la de mantener a toda costa el ganado y las prácticas ganaderas locales en algunas fincas de Doñana. En esos momentos, el núcleo básico de la Asociación respondía a la que había sido la composición tradicional del sector ganadero en Almonte dentro de la estructura social agraria de la comunidad: ciertas familias de pelentrines ${ }^{15}$, no todas, y algunos propietarios mayores, con sus vaqueros profesionales. Empezaron adoptando una estrategia defensiva en torno a las presuntas cualidades biológicas, supuestamente excepcionales, de sus yeguas y vacas mostrencas. Nótese que se autodenominan criadores y no ganaderos (aunque, contradictoriamente, se asociaron a un grupo empresarial andaluz de propietarios agrícolas), y que subrayan, con la referencia toponímica, la idea de la autoctonía de un ganado cuyo estatus biológico consideran idéntico al de las águilas imperiales o los linces, especies salvajes emblemáticas del Parque. Entonces, incluso hoy, para cierto número de yegüerizos estos caballos representaban una raza específica que, dado el frecuente mestizaje, fomentado por ellos mismos, con sementales de calidad u otros caballos domésticos, había ido perdiéndose. La verdad es que no había razón científica alguna que pudiera avalar esa idea. Realmente, en ningún momento de su prolongada estancia en estos llanos, ni las vacas ni los caballos constituyeron un grupo genético o racial netamente diferenciado, sino, en todo caso, un modelo etológico, sólo relativamente singular, adaptado a las condiciones de vida en libertad en un espacio pantanoso.

En pocos años, los yegüerizos y su Asociación fueron optando por argumentos más culturales que biológicos para defender a sus caballos. Habiéndose convertido en secundario su significado económico, los nuevos ganaderos almonteños, mayoritariamente instalados en los sectores

15 Pelantrines. En esta localidad, este término se aplica a agricultores con medianas o pequeñas propiedades, generalmente sin jornaleros a sueldo, salvo durante las recolecciones mayores. 
emergentes de la economía local, tendieron a subrayar que la cría de caballos marismeños era una venerable tradición que estaba siendo socavada por quienes, bajo pretextos conservacionistas, querían restringir el acceso a las Marismas de sus principales protagonistas, desoyendo sus derechos históricos, anteriores a la misma creación del Parque.

Como ya adelantamos, la clave principal para entender las estrategias seguidas por los yegüerizos almonteños en la defensa de sus yeguas en las Marismas de Doñana es su relación con los rituales rocieros. Las últimas novedades incorporadas a la Saca no han hecho más que subrayar y explicitar un nexo que ya estaba implícitamente establecido desde los primeros conflictos con la Administración del Parque (Murphy 1987; Murphy y González Faraco 1996a). Este nexo no se había trenzado en el vacío. Para empezar, la ermita de la Virgen del Rocío está ubicada en los mismos bordes de la Marisma, de la que Ella es "Reina", uno de sus más difundidos títulos. La Aldea del Rocío había sido durante siglos una de las puertas de acceso a los pastos marismeños, cumpliendo el papel de estación ganadera. De hecho, en el siglo xviII la romería fue también feria de ganado con franquicias comerciales (Álvarez Gastón 1978: 102-103) y escenario de un singular conflicto entre propietarios de ganado y colonos agrarios que el Duque de Medina Sidonia quiso establecer, sin éxito, en la que llamó Nueva Población del Rocío (Ojeda 1987: 48).

Por otro lado, si las tácticas seguidas por los almonteños en la defensa de su papel hegemónico en las celebraciones rocieras habían resultado satisfactorias ante diversos oponentes de entidad, por qué no aprender de ellas y extrapolarlas a otras situaciones conflictivas relativamente comparables. Naturalmente, no hablamos de un plan premeditado, sino de la transferencia, entre una situación cultural y otra, de un modus operandi de demostrada funcionalidad y bien conocido por sus actores principales. $\mathrm{Si}$ la hipótesis de Josep M. Comelles (1991) tiene fundamento, y creemos que sí, no sería ésta la primera vez que la devoción a la Virgen del Rocío cumplía adecuadamente la función de ayudar a los almonteños en su deseo de aprovechar los recursos de Doñana. Según este antropólogo, el culto a la Virgen pudo servir a los vecinos de las localidades próximas, y principalmente a los de Almonte, como baza de intervención para encarar, y sortear en lo posible, la paulatina privatización de las tierras de Doñana desde comienzos del siglo xIV y el consecuente aumento de restricciones de paso y uso. En cierto modo, esta función, ya sin su significado económico primitivo, se mantiene cuando cada primavera surgen problemas relacionados con el tránsito de hermandades y romeros a través del actual Parque Nacional.

Los almonteños, como es bien sabido, han desarrollado un particular 
y "agresivo" sistema para conservar su primacía en una peregrinación que ha alcanzado un grado de masificación y popularidad extraordinarias. Este sistema se funda en la proclamación vehemente del Rocío como una tradición local enraizada en el pueblo de Almonte, bajo claras y taxativas indicaciones a las autoridades civiles y religiosas provinciales o regionales y a los foráneos, en general, de que los almonteños están dispuestos a preservarla con todos los medios a su alcance. Uno de los resultados más llamativos de este argumento cultural es la tumultuosa procesión del Lunes de Pentecostés (Murphy 1993), que ha dado a los almonteños su fama de hombres resueltos a defender, a cualquier coste, la que consideran su herencia cultural.

Los yegüerizos, en muchos casos vinculados estrechamente, como ya se apuntó, a la organización de las celebraciones rocieras, han desplegado tácticas similares ante las prohibiciones y regulaciones que las autoridades del Parque han querido imponerles. Éstas han intentado, de una parte, restringir y hasta impedir el acceso a las zonas protegidas de las personas que no participaran directamente en las operaciones del rodeo, durante la Saca de las Yeguas; y de otra, a lo largo de todo el año, controlar y limitar las entradas y los movimientos de los ganaderos y excluir al ganado de algunas áreas de pasto. En otros trabajos ya hemos señalado, con ejemplos, cómo ante estos obstáculos se produce una ritualización lateral que ha favorecido la transferencia de las tácticas rocieras al mundo ganadero, acelerando la redefinición de la Saca de las Yeguas como tradición cultural en la que se ve involucrada toda la comunidad de Almonte en su conjunto, y no sólo los propietarios de yeguas (Murphy 1987; González Faraco y Murphy 1999a y b, 2000).

Uno de los efectos de esta táctica ha sido el incremento espectacular en pocos años del número de miembros de la Asociación ganadera, mientras la evolución del volumen de la cabaña era más lento. Desde hace algún tiempo, la proporción de caballos por propietario es insignificante (entre 1 y 2). Muchos de los nuevos miembros de la Asociación, que ya representan la mayoría numérica, no forman parte del sector económico agropecuario local, y, en bastantes casos, carecen de relación previa personal o familiar con la ganadería marismeña. Sin embargo, se han convertido en nuevos yegüerizos para, por un lado, sumarse a las reivindicaciones de la Asociación y también para integrarse y disfrutar activamente de este mundo de caballos asilvestrados de Doñana. En la épica que relatan las sevillanas sobre estos paisajes llanos por los que discurren caminos rocieros, el héroe es siempre un jinete que cabalga por las Marismas y goza de la libertad en la naturaleza, solo o en compañía de sus amigos, reviviendo las costumbres que considera el legado cultural de su co- 
munidad (González Faraco y Murphy 2001). En el espíritu de estas populares coplas, ser rociero y ser marismeño son una y la misma cosa.

Otro de los efectos conspicuos de estos cambios ha sido el aumento exponencial de espectadores de la Saca de las Yeguas a lo largo de casi todo su desarrollo, pero principalmente en la fase que sucede en la Aldea del Rocío, en la parada que hacen en el camino que las lleva a Almonte y, desde luego, en las mismas calles del pueblo cuando llegan y en los corrales a partir del día siguiente. La venida de las yeguas, que siempre había sido un acontecimiento esperado, es ahora una celebración preeminente de la cultura local para los almonteños, en el preludio y en el desarrollo de su feria patronal.

Desde hace más de veinte años, los yegüerizos y el personal del Parque Nacional han mantenido un rosario de confrontaciones que culminó en 1993, con los sucesos que ya referimos, y en los que hubo un conato de violencia del que se derivó un proceso judicial contra algunos ganaderos y otras personas que participaron en los hechos. La prensa nacional se hizo eco de esta tentativa de "invasión" de ganado en la zona del Parque conocida por Las Marismillas, lo que repercutió desfavorablemente en la reputación que ya tenían los almonteños. La espiral esquismogénica ${ }^{16}$ (Bateson 1958) que siguió a este conjunto de hechos e interpretaciones más o menos afortunadas desembocó, no obstante, después de un prolijo y tortuoso proceso de años, en el primer Plan Ganadero de la historia de

${ }^{16}$ G. Bateson (1958: 175) define esta expresión, esquismogénesis ("schismogenesis"), como a process of differentiation in the norms of individual behavior resulting from culmulative interaction between individuals". Se refiere a la diferenciación progresiva que puede haber en el comportamiento entre dos personas o entidades sociales, al responder una a la intervención de la otra con una reacción parecida pero algo más intensa. Un buen ejemplo podría ser una disputa entre niños en el patio de una escuela: un empujón del primero provoca otro empujón un poco más fuerte del segundo que a su vez provoca un nuevo empujón más fuerte aún del primero, hasta que la disputa deriva en pelea abierta. Para conocer el impacto antropológico del concepto de "schismogenesis" puede recurrirse a la excelente obra de Charles W. Nuckolls (1996: 49-78). Precisamente, el noruego Ottar Brox ha aplicado este concepto a un conflicto entre conservacionistas y granjeros locales en un trabajo (2000). En él analiza una situación inversa a la que se observa en el caso de las yeguas marismeñas. Los conservacionistas noruegos quieren reintroducir lobos, osos y linces en un espacio natural contra el parecer de los granjeros, que temen los riesgos que esta reintroducción de predadores podría comportar para su propia seguridad y la de su ganado. Como consecuencia, se genera un proceso esquismogénico entre quienes llegan desde la ciudad con ánimo de acometer esta "restauración de la naturaleza" (los conservacionistas) y quienes viven cotidianamente del uso de sus recursos (los pobladores locales). 
Doñana, del que ya dimos noticia. Este Plan debería garantizar y regular legalmente la presencia del ganado en la Marismas, y, en cierto sentido, viene a ser una prueba ostensible del éxito alcanzado por la cadena de producciones culturales que hemos venido relatando. Puede suponer, en consecuencia, una base sólida para el futuro desarrollo de unas prácticas culturales que están en pleno proceso de expansión.

Efectivamente, la Saca de las Yeguas que hemos descrito antes contiene muchos elementos de muy reciente incorporación. Hace pocos años, la fase final del rodeo se desarrollaba en el corazón de las Marismas del vecino pueblo de Hinojos. Ahora, tiene lugar en las Marismas de Almonte, a pocos metros de las casas de la Aldea del Rocío. Con este cambio, quedan resueltas, de un golpe, las potenciales, aunque raras, tensiones entre los yegüerizos y el Ayuntamiento de Hinojos, y las que solía haber corrientemente con los responsables del Parque por la presencia de público y vehículos en el interior de la Marisma. Ya son pocos los espectadores que penetran en las zonas protegidas para asistir al rodeo; ahora son muchos más los que asisten a sus últimas evoluciones en la Madre de las Marismas, gracias a su fácil acceso y al hecho de que las yeguas, tras ser reunidas, pasan por las inmediaciones de la ermita del Rocío. Esta novedad en el trayecto seguido por las tropas subraya nítidamente el giro ritual al que hemos hecho mención, reproduciendo, de algún modo, uno de los actos más celebrados de la Romería del Rocío: el paso procesional de las hermandades por delante de la ermita para rendir pleitesía a la Virgen. Como ya dijimos, este paralelismo, que no deja de intensificarse, se repite en la parada que la manada hace en el camino hacia Almonte, cuando nuevamente muchos espectadores acuden y se suman a los ganaderos en animados corrillos donde se bebe y se canta.

Simultáneamente a este estrechamiento de lazos entre las tradiciones ganaderas marismeñas y El Rocío, se ha realzado, como dijimos, el papel de las yeguas en la Feria de San Pedro, una celebración que hace mucho que dejó de ser primordialmente un mercado pecuario (Murphy y González Faraco 1988). Las yeguas vuelven a ser la referencia central de la Feria, su verdadera seña de identidad y distinción dentro de este canon festivo tan extendido por Andalucía. Las autoridades municipales, en colaboración con la Asociación de Criadores, no han dejado de fomentar y difundir, de maneras muy diversas, esta tradición tan singular. Por ejemplo, a través de bandos municipales y cartelería, de su página web o de la prensa que es invitada a acudir a estos actos.

En los últimos años, las labores y transacciones con el ganado, que antes se desarrollaban generalmente en corrales privados, han sido trasladadas a un espacio común, situado a las afueras del pueblo, para posibi- 
litar la concentración masiva de yeguas y de público ${ }^{17}$. En la construcción de la infraestructura necesaria, el Parque Nacional, con sus medios técnicos y financieros, colabora con los ganaderos. En un primer momento, sólo algunos de ellos decidieron quedarse al margen de esta reorganización espacial y, en parte, institucional de la tusa. Su incipiente y breve resistencia ante la patente conversión de la Saca en espectáculo revela, no obstante, un proceso de nostalgia cultural de un tiempo pasado, en el que este suceso era más íntimo, más auténtico, con menos público y sin autoridades presenciándolo. En unas cuantas décadas, una actividad con objetivos meramente instrumentales se ha convertido en un fenómeno expansivo de la cultura expresiva local, con una densidad inusitada de símbolos y ritos aceleradamente elaborados. Es de tal calibre esta aceleración cultural que, en pocos años, ha llegado a generar nostalgia: sin duda, el más claro síntoma de su vertiginosa trasformación como fenómeno social. Éste es también otro elocuente paralelo con lo que ha acontecido en la Romería del Rocío, como lo prueban, entre otras cosas, las letras de las sevillanas escritas en época reciente: en ellas menudea la añoranza de un Rocío pretérito más genuino y menos sofisticado, que la modernización habría desnaturalizado (González Faraco y Murphy 2001).

En junio de 2000, el Ayuntamiento dio una significativa vuelta de tuerca a este proceso de conversión de la Saca en espectáculo público, inaugurando un recinto definitivo en suelo municipal, planeado para dar cabida a las actividades ganaderas. Cuando éstas se celebran, lo dota de aparcamientos vigilados, señalizaciones, mástiles con banderas y cantina, siguiendo las pautas de un espacio ferial. Ha diseñado un corral circular para las exhibiciones públicas con las yeguas (el concurso morfológico), y ha organizado los corrales para las tropas, de manera que la observación de las tareas con los animales sea cómoda. Los visitantes, al llegar al

17 El recinto ganadero municipal se encuentra situado en el camino de Villalba, al noreste del casco urbano. En ese sector han proliferado desordenadamente, en antiguas fincas agrícolas, construcciones para uso fundamentalmente ganadero, los llamados "corralones". En ellos, sus propietarios tienen caballos, perros u otra clase de animales domésticos, amén de la guarnición para la monta, aperos de labranza y otros útiles. En la mayoría de los casos, estos corralones no tienen funciones agropecuarias tradicionales. Son espacios para el ocio y el entretenimiento, en torno a los caballos o a pequeños huertos, para las tardes o los fines de semana. Constituyen, en cualquier caso, un conjunto urbano singular donde, de algún modo, se recrean, a escala menor, las costumbres ganaderas locales por personas que ya mayoritariamente trabajan en el sector servicios de la economía local. A veces, se usan para la tusa o como apoyo durante la presencia de las yeguas en el recinto ganadero municipal. Como conjunto, son también, en cierto modo, una muestra más de la creciente importancia cultural de la ganadería marismeña en la vida local. 
recinto, siguen un recorrido que los conduce progresivamente desde zonas típicamente urbanas (donde dejan sus coches) hasta un amplio espacio vallado en el que algunos grupos de animales pastan tranquilamente, como si repitieran a pequeña escala el camino seguido por los propios yegüerizos al encuentro de las yeguas en la libertad de la Marismas. No suele faltar, en otro sector del recinto, una plaza de toros portátil montada para los festejos taurinos de la Feria.

En su conjunto este recinto representa una proclamación de la identidad local a través de algunos elementos culturales sobresalientes. Sin embargo, y aunque naturalmente no estamos ante una simulación teatralizada, es inevitable pensar, ante esta planeada concentración de signos y símbolos, en los parques temáticos que pretenden reproducir y evocar para los turistas un espectáculo cultural del que sentirse partícipes ${ }^{18}$ (Eco 1986).

Por si fuera poco, las autoridades municipales han erigido, en las inmediaciones de los accesos a la Feria, un conjunto monumental en bronce que representa a un yegüerizo, ataviado a la antigua usanza, arreando a una yegua con su potro. Este conjunto está, además, situado a pocos metros de otro grupo escultórico que reproduce la leyenda de la aparición de la Virgen del Rocío a un cazador (¿o tal vez un pastor que cazaba?), en un lugar selvático limítrofe con los pastos marismeños. A su paso por las inmediaciones, los yegüerizos que conducen las tropas las detienen por unos instantes para honrar a los viejos marismeños en este lugar en el que convergen los simulacros de ambas tradiciones. La cría de caballos asilvestrados en las Marismas, después de haber sido paulatinamente institucionalizada, ha sido finalmente monumentalizada. Un peldaño más para su consagración pública como tradición cimera en la cultura comunitaria que ha de transmitirse a las nuevas generaciones y mostrarse a los turistas.

\section{CONSIDERACIONES FINALES}

Como consecuencia de estas elaboraciones culturales, la cría de yeguas marismeñas parece haber logrado esquivar su desaparición como actividad en el interior del Parque Nacional y asegurar su permanencia en condiciones de regulación aceptables para los ganaderos. Aunque aún es pronto para predecir cómo se desarrollará en el futuro esta actividad, parece que los procesos que hemos venido relatando han contribuido

18 También, en estos últimos aspectos, hay claros paralelismos con algunas tendencias que se vienen observando en las celebraciones rocieras (Cf. Crain 1992; Murphy 1994; Cantero 1996 y 2000; Ostenfeld-Rosenthal 1997; Martínez Moreno 1998 y Comelles 2000). 
además, en concomitancia con otros factores, a un giro histórico en la visión de Doñana como espacio protegido, con un probable impacto en su sistema de conservación. Las yeguas "casi salvajes", en el decir de Chapman, de las Marismas, han encontrado, por fin, su sitio entre las especies del Parque, precisa e irónicamente por haberse integrado más profunda y significativamente en la vida cultural de Almonte. En cierto sentido, de este largo debate entre los yegüerizos y los conservacionistas ha surgido, y éste es un efecto cultural y "casi metafísico" reseñable, el cuestionamiento y la tácita redefinición de cuál es la verdadera naturaleza de la Naturaleza.

Para finalizar, y si se nos permite un ejercicio de especulación prospectiva, todo indica que estamos ante una elaboración cultural inacabada y en expansión. $\mathrm{Y}$, desde luego, ante un proceso pródigo, mayormente reciente, en invención de tradiciones que continúan siendo reinventadas (Hobsbawm y Ranger 1983). Como creemos haber probado y explicado en este trabajo, los almonteños se han inspirado, y no poco, en su particular manera de mantener el control local del Rocío, para asegurar su presencia y la de sus caballos en las Marismas protegidas de Doñana frente a las regulaciones del Estado. En el caso del Rocío, los almonteños han tenido que esforzarse, a veces usando formas agresivas de disuasión, para mantener su protagonismo en unos ritos que han ampliado extraordinariamente su "territorio de gracia" original. El localismo, en su formulación más exhaustiva, ha servido como táctica defensiva de la comunidad frente a la masificación y difusión de la devoción rociera.

En la genealogía de la ganadería marismeña, partimos, hace quinientos años, de un inesperado e histórico impacto internacional gracias a su papel en la colonización americana, fenómeno que, sin embargo, cayó en el olvido y hoy es sólo relativamente conocido. En la actualidad, la cría de caballos y vacas en las Marismas es una tradición estrictamente local, para cuya preservación, ante las normas protectoras del Parque Nacional de Doñana, los ganaderos han ensayado también fórmulas claramente localistas. Nuestra opinión es que, como un escalón más en el despliegue de este localismo, los yegüerizos quizás acaben rememorando el relevante significado internacional de sus caballos asilvestrados, como argumento histórico provechoso para la defensa de su cultura ganadera. Al fin y al cabo, esta estrategia, reafirmar la trascendencia local de la ganadería marismeña a través de su trascendencia universal, no distaría mucho de la que los conservacionistas emplean para reforzar el valor ecológico de Doñana e instigar su defensa: considerarlo como patrimonio de toda la humanidad. 


\section{BIBLIOGRAFÍA CITADA}

ADAmS, R. F. 1945. Western Words: A Dictionnary of the Range, Cowcamp and Trail. Norman: University of Oklahoma.

Álvarez GaStón, R. 1978. Almonte y El Rocío. Esperanzas de un pueblo andaluz. Sevilla: Editorial Católica Española.

Bateson, G. 1958: Naven: A Survey of the Problems Suggested by a Composite Picture of the Culture of a New Guinea Tribe Drawn from Three Points of View. Stanford University Press, $2 .^{\mathrm{a}}$ ed.

BENNET, D. 1998. Conquerors. The Roots of New World Horsemanship. Solvang, California: Amigo Publications Inc.

Berger, J. 1986. Wild Horses of the Great Basin: Social Competition and Population Size. The University of Chicago Press.

BERnUÉs, M. y C. MONTES. 1994. Base bibliográfica para el estudio del medio natural del Parque Nacional de Doñana y su entorno. Madrid: Agencia de Medio Ambiente.

BILGER, B. 1991. "The Return of the Wild Horse". Oklahoma Today 41 (4): 10-17.

Bishko, Ch. J. 1952. "The Peninsular Background of Latin American Cattle Ranching". The Hispanic American Historical Review 32 (4): 491-515.

BoYD, L. y K. A. HoupT (eds.). 1994. Przewalski's Horse: the History and Biology of an Endangered Species. Albany: Suny Press.

Brown, C. K. 1992. "Wild Horses of the Outer Banks". Trilogy 4 (5): 84-88.

BROX, O. 2000: "Schismogenesis in the Wilderness: The Reintroduction of Predators in Norwegian Forests". Ethnos 65 (3): 387-404.

Butzer, K. W. 1988. "Cattle and Sheep from Old to New Spain: Historical Antecedents". Annals of the Association of American Geographers 78 (1): 29-56.

CABADA CASTRO, M. 1992. A Rapa das Bestas de Sabucedo. Historia e Antropoloxía dunba tradición. Vigo: Ir Indo Edicións.

CAmpos PalaCín, P. y J. LóPez LinAge. 1998. Renta y naturaleza en Doñana: a la búsqueda de la conservación con uso. Icaria: Madrid.

CANTERO, P. A. 1996. "El Rocío. Significados y sentidos de un culto andaluz". Documento inédito.

-. 2000. “El Vuelo de la Alondra: las fiestas religiosas de Andalucía, entre la imagen y el orden, el ocio y el negocio", en D. González Cruz (ed.), Religiosidad y costumbres populares en Iberoamérica: 169-83. Universidad de Huelva, Servicio de Publicaciones.

CARmona RuIz, M. A. 1998. La ganadería en el Reino de Sevilla durante la Baja Edad Media. Sevilla: Diputación Provincial de Sevilla.

CASTroviejo, J. 1993. Mapa del Parque Nacional de Doñana. Madrid: CSIC y Agencia de Medio Ambiente de la Junta de Andalucía.

Chapman, A. y W. J. Buck. 1893. Wild Spain: Records of Sport with Rifle, Rod, and Gun. Natural History and Exploration. Londres: Gurney and Jackson.

- 1910. Unexplored Spain. Londres: E. Arnold.

COATES-MARKLE, L. 1997. "Choosing to Survive". Equus 231: 34-41.

Comelles, J. M. 1991. "Los caminos del Rocío", en J. Prat, U. Martínez, J. Contreras e I. Moreno (eds.) Antropología de los Pueblos de España: 755-770. Madrid: Taurus Ediciones. 
-. 2000. "El Rocío en la cultura de masas. Representaciones identitarias y conflictos culturales en el nuevo milenio", en J. Hurtado Sánchez (comp.), Religiosidad Popular Sevillana: 123-150. Sevilla: Universidad y Ayuntamiento de Sevilla.

Crain, M. M. 1992. "Pilgrims, Yuppies, and Media Men: The Transformation of an Andalusian Pilgrimage", en J. Boissevain, (ed.), Revitalizing European Rituals: 95112. Londres: Routledge.

CRUZ, L. 1908. Documentos de las Fundaciones Religiosas de la Villa de Almonte y Apuntes para su Historia. Huelva: Imprenta Gálvez.

Del Moral Ituarte, L. 1993. "Medios húmedos. Las Marismas del Guadalquivir", en Ojeda Rivera, J. F. et al., Intervenciones públicas en el Litoral Atlántico Andaluz. Efectos territoriales: 31-40. Sevilla: Junta de Andalucía, Consejería de Cultura y Medio Ambiente.

DOBBIE, W. R.; D. M. BERMAN y M. L. BRAYSHER. 1994. Managing Vertebrate Pets: Feral Horses. Australia: Bureau of Rural Services.

DoBIE, J. F. 1934. The Mustangs. Nueva York: Bramhall House.

Doolittle, W. E. 1987. "Las Marismas to Pánuco to Texas: The Transfer of Open Range Cattle Ranching from Iberia through Northeastern Mexicon. Proceedings of the Conference of Latin Americanist Geographers 13: 3-11.

DunCAN, P. 1992. Horses and Grasses: The Nutritional Ecology of Equids and Their Impact on the Camargue. Nueva York: Springer-Verlag.

ECO, U. 1986. Travels in Hyperreality. Orlando: Harcourt Brace Jovanovich.

EDWARDS, E. H. 1992. Leading the Field: British Native Breeds of Horses and Ponies. Londres: Stanley Paul.

-. 1995. Wild Horses of the World. Grantown-on-Spey, Escocia: Colin Baxter Photography.

FoOD AND AGRICUltural ORganization OF the United NATIONS. 1986. The Przewalski Horse and Restoration to its Natural Habitat in Mongolia. Roma: FAO, Animal Production and Health, Doc. n. ${ }^{9} 61$.

GONZÁleZ ARTEAGA, J. 1992. Las Marismas del Guadalquivir: etapas de su aprovechamiento económico. Sevilla: Servicio de Publicaciones de la Universidad de Sevilla.

GONZÁlez Faraco, J. C. 1991a. "La evolución de los usos tradicionales en los espacios naturales protegidos". Vida Silvestre 69: 8-15.

- 1991b. "Efectos del cambio social en una práctica ganadera tradicional: la cría de caballos en las Marismas de Doñana». Agricultura y Sociedad 59: 245-268.

GonZález Faraco, J. C. y M. D. MurPhy. 1999a. "La Saca de las Yeguas en las Marismas de Doñanam. Narria: Revista de Artes y Costumbres Populares 81/84: 33-44.

—. 1999b. "El Rocío: la evolución de una Aldea Sagrada". Aestuaria 6: 89-132.

- 2000. "La cultura ganadera en el Parque Nacional de Doñana", en $V$ Encuentro de Escritores del Entorno de Doñana: 119-144. Huelva: Fundación Odón Betanzos.

- 2001. "La construcción cultural del paisaje: Doñana en las sevillanas rocieras", en XIX Coloquio Metodológico-Didáctico de Hespérides: 11-35. Alcalá la Real, Jaén: Asociación de Profesores de Geografía e Historia de Bachillerato de Andalucía.

Granados Corona, M. 1989. Transformaciones históricas de los ecosistemas del Parque Nacional de Doñana. Universidad de Sevilla. Tesis de Doctorado.

GraYson, P. 1998. Mountain and Moorland Ponies of the British Isles. Londres: Kingdom Books.

HobsBawm, E. y T. RANGER (eds.). 1983. The Invention of Tradition. Cambridge University Press. 
JORDAN, T. G. 1989. "An Iberian Lowland/Highland Model for Latin American Cattle Ranching. Journal of Historical Geography 15 (2): 111-125.

- 1993. North American Cattle-Ranching Frontiers: Origins, Diffusion, and Differentiation. Alburquerque: University of New Mexico Press.

KIFF, S. 1972. The Use of Land by the Commoners of the New Forest. Londres: University College. Discussion Papers in Conservation.

KirkPATRICK, J. F. 1994. Into the Wind: Wild Horses of North America. Minocqua, Wisconsin: NorthWord Press.

KuINGER, H. A. 1974. "A Comparison of the Social Behavior of the Equidae", en V. Geist y F. Walther (eds.), The Behavior of Ungulates and Its Relation to Management: 124-132. IUCN New Series $\mathrm{n}^{\circ}$ 24. Morges: IUCN.

KrautwurST, T. 2000. "Running Wild". National Geographic World 294:14-18.

LAzo, A. 1992. Socioecología del ganado bovino asilvestrado de la Reserva Biológica de Doñana. Universidad de Sevilla. Tesis Doctoral.

-. 1995. "Relevancia ecológica de los herbívoros domésticos. El ganado como herramienta de conservación de espacios naturales". Quercus 116: 31-33.

- 1996. I Concurso Morfológico de la Vaca Mostrenca en Doñana. Almonte, Huelva: Asociación de Criadores de Ganado Marismeño. Documento policopiado.

MÁrQuez GUITART, J. M. 1998. El pueblo de Almonte a sus yeguas y yegüerizos. Huelva: Ayuntamiento de Almonte.

MARTÍNEZ MORENO, R. M. 1998. "La romería del Rocío, una fiesta de la posmodernidad". Gazeta de Antropología 13: 45-58.

MCCORT, W. D. 1984. "Behavior of Feral Horses and Ponies". Journal of Animal Science 58 (2): 493-499.

McKNight, T. L. 1959. "The Feral Horse in Anglo-America". Geographical Review 49: 506-525.

-. 1976. "Friendly Vermin: A Survey of Feral Livestock in Australia". University of California Publications in Geography 21: 1-104.

MiLlER, R. 1986. "A Review of Feral Horse Research Pertinent to the Reintroduction of Przewalski's Horses", en The Przewalski Horse and Restoration to its Natural Habitat in Mongolia: 135-141. Roma: FAO Animal Production and Health, doc. n. ${ }^{9} 61$.

MilleR, R. y R. H. DENNISTON. 1979. "Interband Dominance in Feral Horses". Zeitschrift fur Tierpsychologie 51: 41.

MORENO, I. 1995. "El Rocío: de romería de las Marismas a fiesta de identidad andaluza", en A. Fraguas et al. (coords.), Romarias e peregrinacións. Simposio de Antropoloxía: 121-141. Santiago de Compostela: Consello da Cultura Galega.

MuRPHY, M. D. 1987. "Marsh Mares of Almonte". The World and I 2 (5): 452-469.

-. 1993. "The Politics of Tumult in an Andalusian Ritual". PoLAR: Political and Legal Anthropology Review 16 (2): 75-84.

-. 1994. "Class, Community and Costume in an Andalusian Pilgrimage". Anthropological Quarterly 67: 49-61.

MurPhy, M. D. y J. C. GonZÁlez Faraco. 1988. "Fiesta in Almonte. The World and I 3 (7): 480-491.

- 1996a. "La feria de las yeguas: de regreso a los orígenes". Revista de Feria: 22-25.

-. 1996b. "Masificación ritual, identidad local y toponimia en El Rocío", Demófilo. Revista de Cultura tradicional de Andalucía 20: 101-120.

-. (coords.). 2002a. El Rocío: análisis culturales e históricos. Huelva: Diputación Provincial. Colección Investigación. Serie Antropología, n. 38 . 
- 2002b. "Los nombres de la Virgen del Rocío: imagen, territorio y comunidad en la evolución de una nomenclatura marianan, en D. González Cruz (ed.), Ritos y ceremonias en el mundo bispano durante la Edad Moderna: 179-198. Huelva: Servicio de Publicaciones de la Universidad de Huelva.

Nichols, M. W. 1939. "The Spanish Horse of the Pampas". American Anthropologist 41: 119-29.

NucKolls, Ch. W. 1996. The Cultural Dialectics of Knowledge and Desire. Madison: University of Wisconsin Press.

OJEDA RIVERA, J. F. 1987. Organización del territorio en Doñana y su entorno próximo Almonte. Siglos XVII-XX. Madrid: ICONA, monografía n. 94.

- 1993. Doñana, esperando a Godot. Cuadernos del Instituto de Desarrollo Regional n..$^{-}$31. Sevilla: Instituto de Desarrollo Regional, Universidad de Sevilla.

- et al. 1993. Intervenciones públicas en el Litoral Atlántico Andaluz. Efectos territoriales. Sevilla: Junta de Andalucía, Consejería de Cultura y Medio Ambiente.

Ostenfeld-Rosenthal, A. 1997. "A Celebration of Andalusia: A Performative Approach to an Andalusian Pilgrimage». Folk 39: 103-121.

Pereladova, O. B. et al. 1999. "Przewalski's horse: Adaptation to Semi-Wild Life in Desert Conditions". Oryx 33 (1): 47-58.

Pérez Martínez, J. M. 1992. Experiencia en Doñana. Homenaje a nuestros abuelos. Huelva: Ayuntamiento de Almonte.

Plan de Aprovechamiento Ganadero del Parque Nacional de Doñana. Documento policopiado, 2001.

POLlOCK, J. 1980. Behavioural Ecology and Body Condition Changes in New Forest Ponies. Londres: RSPCA Scientific Publications.

Rodríguez BeCERRA, S. 1989. "La romería del Rocío, fiesta de Andalucía". El Folklore Andaluz 3: 147-152.

ROlDÁn CASTRO, F. 1997. Niebla musulmana. Huelva: Diputación Provincial.

SHEAF, E. T. 1903. "The Ponies of the New Forest". Outing XLI: 415-418.

TINKER, E. L. 1967. The Horsemen of the Americas and the Literature They Inspired. Austin: University of Texas Press.

Tyler, S. J. 1972. "The Behaviour and Social Organization of the New Forest Ponies". Animal Behaviour Monographs 5, II parte: 87-196.

VALVERDE, J. A. 1960. "Vertebrados de las Marismas del Guadalquivir. Introducción a su estudio ecológico". Archivos del Instituto de Aclimatación de Almería 9: 9-166.

Verner, Col. W. 1909. My Life Among the Wild Birds of Spain. Londres: John Bale, Sons \& Danielsson, Ltd.

WORCESTER, D. 1986. The Spanish Mustang: From the Plains of Andalusia to the Prairies of Texas. El Paso: The Texas Western Press, University of Texas.

WyMAN, W. D. 1945. The Wild Horse of the West. Lincoln: University of Nebraska Press.

ZARN, M.; Th. Heller y K. Collins. 1977. "Wild, Free-Roaming Horses: Status of Present Knowledge. Technical Note 294. Denver, Colorado: U.S. Department of the Interior (Bureau of Land Management) y U.S. Department of Agriculture (U.S. Forest Service). 